\title{
A Study of Clinical Profile and Neutrophil- Lymphocyte Ratio in Clinical Outcome of Covid 19 Patients: Tertiary Care Centre in Bangalore
}

\author{
Mamatha Tittamegalapalya Ramalingaiah ${ }^{*}$, Jeetendra Kumar Jogihalli Mood ${ }^{2}$, Vinutha Bagalur Srinivas \\ Murthy ${ }^{3}$, Virender Singh ${ }^{4}$
}

${ }^{1}$ Assistant Professor, Department of Medicine, ESIC \& PGIMSR Bengaluru, Karnataka, India

${ }^{2}$ Dean \& Professor, Department of Medicine, ESIC \& PGIMSR, Bengaluru, Karnataka, India

${ }^{3}$ Resident, Department of Medicine, ESIC \& PGIMSR, Bengaluru, Karnataka, India

${ }^{4}$ Resident, Department of Medicine, ESIC \& PGIMSR, Bengaluru, Karnataka, India

*Corresponding Author: Dr. Mamatha T.R; dr.mamatha87@gmail.com

Received 31 July 2021;

Accepted 22 August 2021;

Published 03 September 2021

\begin{abstract}
Introduction: Corona virus disease is ongoing global pandemic, caused by severe acute respiratory distress syndrome corona virus 2 (SARSCov2). The virus was first identified in Wuhan, China in December 2019. The World Health Organization declared the virus a Public Health Emergency of International Concern on 30 January 2020, and later a pandemic on 11 March 2020.The severity of COVID-19 symptoms can range from asymptomatic milder forms to life-threatening. Severe illness is more likely in elderly patients and also in patients with co morbid conditions. Disease can transmit through air contaminated by droplets and small airborne particles. $\underline{\text { Aims: }}$ : we aimed to know the clinical profile of covid 19 patients and also to co relate the neutrophil-lymphocyte ratio with clinical outcome of the disease. Materials and methods: This Prospective study was conducted in Patients admitted from August 2020 to October 2020. COVID-19 infection was diagnosed by RT-PCR and rapid antigen test (RAT) technique. Patients demographic data, clinical history was collected. Clinical assessment was performed. Laboratory investigations was sent. Patients were followed during the hospital stay. Appropriate statistical analysis was used $\underline{\text { Results: }}$ Males were commonly affected than females. Mean age of the patient was 61 years. Diabetes was the most common co morbid condition. Fever was the most common symptom followed by cough, breathlessness. Neutrophil-lymphocyte ratio was elevated in intubated patients than in patients maintaining room air saturation, which was statistically significant ( $p$ value 0.001). Conclusion: Neutrophil-lymphocyte ratio (NLR) can be used as reliable, early marker for the disease progression of covid 19 disease.
\end{abstract}

Keywords: Corona virus, CRP, D-dimer

\section{Introduction}

Corona viruses are non-segmented positive-stranded RNA viruses with a roughly $30 \mathrm{~kb}$ genome surrounded by a protein envelope. Most corona viruses cause diseases in their particular host species [1]. Those that can infect humans through cross-species transmission have become an important threat to public health. Two serious corona virus disease outbreaks have happened in the past two decades: severe acute respiratory syndrome (SARS) in $2003^{[2]}$ and Middle East respiratory syndrome (MERS) [3] in 2012. Since December, 2019, severe acute respiratory syndrome corona virus 2 (SARS-CoV-2) has been recognized as the causal factor in a series of severe cases of pneumonia originating in Wuhan in Hubei province, China ${ }^{[4]}$. This disease has been named corona virus disease 2019 (COVID-19) by WHO. SARS-CoV-2 has been shown to cause disease via a mechanism analogous to the
SARS corona virus, with potential damage to vital organs such as lung, heart, liver, and kidney, and infection poses a considerable risk to patients by the high prevalence of pneumonia ${ }^{[5]}$. The majority of cases are usually self-limiting with low-grade fever, sore throat, myalgia and cough ${ }^{[6]}$, in others, disease can be progressed to severe disease in the form of acute respiratory distress syndrome and it can be fatal ${ }^{[6]}$. SARS Cov 2 infection in patients with preexisting co-morbidities have poor outcome ${ }^{[7]}$. Physicians are searching for a reliable prognostic marker that can distinguish patients at risk of developing more severe forms of the disease and can reduce mortality. The neutrophil-to-lymphocyte ratio (NLR) in peripheral blood has been studied as a systemic inflammatory marker and various studies have shown that it is a valid prognostic factor in various solid tumours ${ }^{[8]}$. In our study, we aimed to know the neutrophil-lymphocyte ratio in milder and severe forms of covid 19 disease. 


\section{Aims and objectives of the study}

1. To study the clinical profile and biochemical markers in covid-19 patients.

2. To correlate Neutrophil- lymphocyte ratio with clinical outcome of the disease

\section{Materials and Methods}

This Prospective study was conducted in Patients admitted in ESIC \& PGIMSR, Rajajinagar, Bangalore from August 2020 to October 2020. COVID-19 infection was diagnosed by RT-PCR and rapid antigen test (RAT) technique. Patients data like age, sex, clinical symptoms and co morbidities like hypertension, diabetes, metabolic disorders, cardiac disorders, respiratory disorders was confirmed by patients history. All patients were followed during hospital stay. Biochemical markers like CRP, d-dimer, neutrophillymphocyte ratio were assessed and it was co-related with outcome of the disease.

\section{Inclusion Criteria:}

1. Patient willing to give informed consent

2. Patients with age more than 18 years

3. Patients diagnosed with COVID-19 infection by RT-PCR technique or RAT test

\section{Exclusion Criteria:}

1. Patient not willing to give informed consent

2. Age less than 18 years.

\section{Statistical Analysis}

Data was entered in the excel spread sheet. SPSS (Statistical Package for Social Sciences) version 20. [IBM SPSS statistics (IBM corp. Armonk, NY, USA released 2011)] was used to perform the statistical analysis. Descriptive statistics of the explanatory and outcome variables were calculated by mean, standard deviation for quantitative variables, frequency and proportions for qualitative variables. Chi square was applied to test the statistical association between qualitative variables. ANOVA test was applied to test the statistical significance for more than two groups for quantitative data. The level of significance was set at $5 \%$

\section{Results}

Table 1: Co relation of clinical outcome with gender of covid 19 patients

\begin{tabular}{|c|c|c|c|c|c|}
\hline \multirow[t]{2}{*}{ Gender } & \multicolumn{4}{|l|}{ OUTCOME } & \multirow[t]{2}{*}{ Total } \\
\hline & Intubation & Noninvasive ventilation & Oxygen requirement & Room air & \\
\hline \multirow[t]{2}{*}{ Male } & 5 & 18 & 15 & 22 & 60 \\
\hline & $8.3 \%$ & $30.0 \%$ & $25.0 \%$ & $36.7 \%$ & $100.0 \%$ \\
\hline \multirow[t]{2}{*}{ Female } & 1 & 10 & 17 & 12 & 40 \\
\hline & $2.5 \%$ & $25.0 \%$ & $42.5 \%$ & $30.0 \%$ & $100.0 \%$ \\
\hline \multirow[t]{2}{*}{ Total } & 6 & 28 & 32 & 34 & 100 \\
\hline & $6.0 \%$ & $28.0 \%$ & $32.0 \%$ & $34.0 \%$ & $100.0 \%$ \\
\hline
\end{tabular}

In our study, $60 \%(60)$ of the subjects were male and $40 \%(40)$ ) of the subjects were female. Male were predominantly affected by covid 19 infection. Overall, $34 \%$ of the patient were maintaining in room air saturation. $32 \%$ of the patient required oxygen support. $28 \%$ of the patient required noninvasive ventilation. $6 \%$ of the patient required intubation

Table 2: Clinical profile of covid 19 patients and co relation with clinical outcome of the disease

\begin{tabular}{|c|c|c|c|c|c|c|}
\hline \multirow{2}{*}{ Clinical features } & \multicolumn{4}{|c|}{ OUTCOME } & \multirow{2}{*}{ Total } & \multirow{2}{*}{ p value* } \\
\hline & Intubation & Non-invasive ventilation & Oxygen requirement & Room air & & \\
\hline \multirow{2}{*}{ Fever } & 3 & 26 & 32 & 30 & 91 & \multirow{2}{*}{$0.018^{\#}$} \\
\hline & $3.3 \%$ & $28.6 \%$ & $35.2 \%$ & $33.0 \%$ & $100.0 \%$ & \\
\hline \multirow{2}{*}{ Cough } & 4 & 25 & 30 & 25 & 84 & \multirow{2}{*}{$0.234^{*}$} \\
\hline & $4.8 \%$ & $29.8 \%$ & $35.7 \%$ & $29.8 \%$ & $100.0 \%$ & \\
\hline \multirow{2}{*}{ Breathlessness } & 6 & 28 & 31 & 0 & 65 & \multirow{2}{*}{$0.001^{\#}$} \\
\hline & $9.2 \%$ & $43.1 \%$ & $47.7 \%$ & $0.0 \%$ & $100.0 \%$ & \\
\hline \multirow{2}{*}{ Myalgia } & 4 & 18 & 25 & 23 & 70 & \multirow{2}{*}{$0.814^{*}$} \\
\hline & $5.7 \%$ & $25.7 \%$ & $35.7 \%$ & $32.9 \%$ & $100.0 \%$ & \\
\hline \multirow{2}{*}{ Sore throat } & 4 & 22 & 25 & 15 & 66 & \multirow{2}{*}{$0.023^{\#}$} \\
\hline & $6.1 \%$ & $33.3 \%$ & $37.9 \%$ & $22.7 \%$ & $100.0 \%$ & \\
\hline
\end{tabular}

*Yate's chi square test \#Significant

$91 \%$ of the patients had fever, out of that, $35.2 \%$ (32) of the patient required oxygen support, $28.6 \%(26)$ of the patient required noninvasive ventilation and $3.3 \%$ (3) of the patient required intubation which was statistically significant. 66 patients had sore throat, out of that,37.9\% (25) patients required oxygen support, 33.3\%(22) of the patient required non-invasive ventilation and $6.1 \%$ (4) of the patient required intubation, which was statistically significant. 65 patients had breathlessness, out of that, $47.7 \%$ (31) required oxygen support, $43.1 \%$ (28) of the patient required non-invasive ventilation and $9.2 \%$ (6) of the patient required intubation which was statistically significant. However, 84 patients had cough and 70 patients had myalgia which was not statistically significant with outcome of the disease.

Most common symptoms was fever $(91 \%)$ followed by cough $(84 \%)$, myalgia $(70 \%)$, sorethorat $(66 \%)$ and breathlessness $(65 \%)$. 
Table 3: Co relation of age, biochemical markers with clinical outcome of covid 19 patients

\begin{tabular}{|c|c|c|c|c|c|c|c|c|}
\hline Variables & Outcome & $\mathbf{N}$ & Mean & SD & Min & Max & F value* & p value \\
\hline \multirow{5}{*}{ Age } & Intubation & 6 & 61.00 & 10.33 & 50 & 75 & \multirow{5}{*}{3.777} & \multirow{5}{*}{$.013^{\#}$} \\
\hline & NIV & 28 & 54.86 & 11.71 & 36 & 80 & & \\
\hline & $\mathrm{O} 2$ requirement & 32 & 52.72 & 14.95 & 19 & 82 & & \\
\hline & Room air & 34 & 45.38 & 14.83 & 20 & 80 & & \\
\hline & Total & 100 & 51.32 & 14.42 & 19 & 82 & & \\
\hline \multirow{5}{*}{ HB } & Intubation & 6 & 11.32 & 2.63 & 6.8 & 13.9 & \multirow{5}{*}{0.663} & \multirow{5}{*}{0.577} \\
\hline & NIV & 28 & 11.70 & 1.90 & 7.6 & 15.9 & & \\
\hline & $\mathrm{O} 2$ requirement & 32 & 12.28 & 1.98 & 5.8 & 16.0 & & \\
\hline & Room air & 34 & 11.81 & 2.09 & 7.5 & 16.3 & & \\
\hline & Total & 100 & 11.90 & 2.02 & 5.8 & 16.3 & & \\
\hline \multirow{5}{*}{ TLC } & Intubation & 6 & 12,180 & 6,985 & 4500 & 25300 & \multirow{5}{*}{2.322} & \multirow{5}{*}{0.080} \\
\hline & NIV & 28 & 11,145 & 5,078 & 4000 & 28730 & & \\
\hline & $\mathrm{O} 2$ requirement & 32 & 9,378 & 4,541 & 3980 & 25400 & & \\
\hline & Room air & 34 & 8,478 & 3,807 & 3000 & 23000 & & \\
\hline & Total & 100 & 9,735 & 4,722 & 3000 & 28730 & & \\
\hline \multirow{5}{*}{$\mathrm{N} \%$} & Intubation & 6 & 90.00 & 3.85 & 84 & 94 & \multirow{5}{*}{28.398} & \multirow{5}{*}{$0.001^{\#}$} \\
\hline & NIV & 28 & 82.75 & 7.69 & 61 & 95 & & \\
\hline & $\mathrm{O} 2$ requirement & 32 & 78.56 & 7.62 & 56 & 95 & & \\
\hline & Room air & 34 & 66.50 & 9.50 & 44 & 78 & & \\
\hline & Total & 100 & 76.32 & 11.09 & 44 & 95 & & \\
\hline \multirow{5}{*}{$\mathrm{L} \%$} & Intubation & 6 & 4.67 & 1.37 & 3 & 7 & \multirow{5}{*}{117.666} & \multirow{5}{*}{$0.001^{\#}$} \\
\hline & NIV & 28 & 12.25 & 2.76 & 7 & 18 & & \\
\hline & $\mathrm{O} 2$ requirement & 32 & 17.25 & 4.20 & 10 & 30 & & \\
\hline & Room air & 34 & 32.35 & 6.86 & 20 & 46 & & \\
\hline & Total & 100 & 20.23 & 10.46 & 3 & 46 & & \\
\hline \multirow{5}{*}{$\mathrm{N}: \mathrm{L}$} & Intubation & 6 & 20.75 & 6.44 & 12.7 & 31.3 & \multirow{5}{*}{183.983} & \multirow{5}{*}{$0.001^{\#}$} \\
\hline & NIV & 28 & 6.98 & 1.50 & 5.0 & 11.1 & & \\
\hline & $\mathrm{O} 2$ requirement & 32 & 4.77 & 1.21 & 1.8 & 8.0 & & \\
\hline & Room air & 34 & 2.10 & 0.58 & 1.0 & 3.3 & & \\
\hline & Total & 100 & 5.44 & 4.70 & 1.0 & 31.3 & & \\
\hline \multirow{5}{*}{ CRP } & Intubation & 6 & 98.17 & 36.78 & 54.0 & 150.0 & \multirow{5}{*}{110.550} & \multirow{5}{*}{$0.001^{\#}$} \\
\hline & NIV & 28 & 38.40 & 14.31 & 18.6 & 72.0 & & \\
\hline & $\mathrm{O} 2$ requirement & 32 & 16.33 & 11.74 & .8 & 43.0 & & \\
\hline & Room air & 34 & 1.76 & 0.56 & .6 & 3.1 & & \\
\hline & Total & 100 & 22.46 & 27.31 & .6 & 150.0 & & \\
\hline \multirow{5}{*}{ D-DIMER } & Intubation & 6 & 11.78 & 4.02 & 7.9 & 19.2 & \multirow{5}{*}{121.472} & \multirow{5}{*}{$0.001^{\#}$} \\
\hline & NIV & 28 & 6.09 & 1.61 & 3.1 & 8.8 & & \\
\hline & $\mathrm{O} 2$ requirement & 32 & 3.56 & 1.61 & .7 & 7.2 & & \\
\hline & Room air & 34 & 0.57 & 0.31 & .1 & 1.2 & & \\
\hline & Total & 100 & 3.75 & 3.36 & .1 & 19.2 & & \\
\hline
\end{tabular}

\section{*ANOVA \#Significant}

Among intubated patients, mean age of the patients was 61years, which was statistically significant with outcome of the disease. As we know, age is also risk factor for severity of the disease. Elderly people are more prone for developing severe disease.9 Mean CRP was 98.17 in intubated patients and 1.76 in patients with room air, which is statistically significant( $\mathrm{p}$ value $<0.001)$. Mean value of $d$ dimer in intubated patients was 11.78 and 0.57 in patients with room air which is statistically significant. Mean value of Neutrophil and lymphocyte ratio was 20.7 in intubated patients and 2.1 in patients with maintaining room air saturation, which is statistically significant. Mean value of neutrophil percentage count was 90 in intubated patients and 66.5 in patients with maintaining room air saturation, which is statistically significant. Mean value of lymphocyte percentage count was 4.67 in intubated patients and 32.35 in patients with maintaining room air saturation, which is statistically significant. However, haemoglobin, total leukocyte count was not statistically significant in our study.

\section{Discussion}

In our study, $60 \%$ males were predominantly affected. Metaanalysis conducted by Biswas $\mathrm{M}$ et al concluded that males were predominantly affected, and more risk for severe form of disease ${ }^{[9]}$.

In our study, we found that, elderly patients, mean age of 61 years were more affected with severe form of the disease. Bonanad $\mathrm{C}$ et al concluded the largest increase in mortality risk was observed in patients aged 60 to 69 years ${ }^{[10]}$.

In our study, we found that $65 \%$ patients had diabetes, $15 \%$ patients had hypertension, $11 \%$ patients had ischemic heart disease, $4 \%$ patients had hypothyroid, 5\% patients had asthma. 
Diabetes was the most common co morbid conditions associated with covid 19 infection. A study conducted by Osibogun et al concluded that co-morbidities are prevalent and the associated risk of death is high among COVID-19 patient ${ }^{[11]}$. A study conducted by Gold et al concluded that hypertension (47.65\%) was more prevalent followed by diabetes $(24.89 \%)^{[12]}$.

Haemoglobin was not statistically significant in our study. A study conducted by Hariyanto et al concluded anemia seems to be associated with an enhanced risk of severe COVID-19 infection ${ }^{[13]}$. It has been suggested that neutrophils enhance antiviral defenses by interaction with other immune cell populations, virus internalization and killing mechanism, cytokines release, degranulation, oxidative burst, and neutrophil extracellular traps (NETs) ${ }^{[14,15]}$. Neutrophilia has been described as an indicator of severe respiratory symptoms and a poor outcome in patients with COVID-19 ${ }^{[16,17,18]}$. In our study, $90 \%$ of the neutrophil was found in intubated patient and $66.5 \%$ in patients with maintaining room air, which is statistically significant. Lymphopenia are prominent laboratory abnormalities reported in patients with SARS, and these conditions are more frequent in patients with severe disease compared to non-severe disease ${ }^{[19]}$. Lymphopenia is also observed in approximately $60 \%$ of patients with SARS-CoV-2 infection at initial presentation ${ }^{[20]}$. In our study, $4.67 \%$ of lymphocytes was found in patients with intubated and $32.35 \%$ in patients with maintaining room air saturation, which was statistically significant. Mean CRP was 98.17 in intubated patients and 38.40 in non-invasive ventilated patients, 16.33 in oxygen support and 1.76 in patients with maintaining room air saturation, which was statistically significant. This indicates CRP was increased in severe form of covid 19 infection than compared to milder form of disease. A study conducted by Sahu et al concluded that Concentrations of CRP remained high in patients who died of COVID-19 infection and could be a promising biomarker for assessing disease lethality ${ }^{[21]}$. A study conducted by Wang, L concluded that, in the early stage of COVID-19 CRP levels were positively correlated with lung lesions and could reflect disease severity ${ }^{[22]}$. A study conducted by chen et al concluded that, the level of plasma CRP was positively correlated to the severity of COVID-19 pneumonia ${ }^{[23]}$. In our study, we found that dimer was 11.78 in intubated patients, 6.09 in non-invasive ventilated patients, 3.56 in patients with oxygen support and 0.57 in patients with maintaining room air saturation. This reflects $\mathrm{d}$ dimer level was increased in severe form of disease. A study conducted by Yao concluded that d-dimer is commonly elevated in patients with COVID-19 and d-dimer levels correlate with disease severity and are a reliable prognostic marker for in-hospital mortality in patients admitted for COVID-19 ${ }^{[24]}$. A study conducted by Yu concluded that d-dimer level is associated with the severity of COVID-19 ${ }^{[25]}$.

In our study, we found that neutrophil-lymphocyte ratio was 20.75 in intubated patients, 6.98 in non invasive ventilated patient, 4.77 in patients with oxygen support and 2.10 in patients with maintaining room air. This indicates neutrophil-lymphocyte ratio reflects disease severity, can be taken as prognostic marker for the disease. A study conducted by yang et al concluded that NLR can be considered independent biomarkers for indicating poor clinical outcomes ${ }^{[26]}$. A study conducted by iran et al, concluded that NLR can be used as an early warning signal for deteriorating severe COVID-19 infection ${ }^{[27]}$. A study conducted by Li et al, concluded that, NLR has good predictive values on disease severity and mortality in patients with COVID-19 infection ${ }^{[28]}$. A study conducted by Usul et al., concluded, NLR was was found to be significantly high in critically ill COVID-19 patients compared to the control population ${ }^{[29]}$. A study conducted by gustavo et al, concluded that high neutrophil to lymphocyte ratio as a prognostic marker in COVID-19 patients ${ }^{[30]}$.

\section{Conclusion}

Neutrophil-lymphocyte ratio is significantly increased in patients with intubated patients than in patients requiring only oxygen support and in patients maintaining room air saturation. So, this indicates that neutrophil-lymphocyte ratio can reflect the disease progression. It can used as simple, reliable, early prognostic marker for the severity of covid-19 disease. Patients with high levels of neutrophil-lymphocyte ratio has higher risk of deterioration. So, such patients may be considered for early admission to critical care unit.

\section{Acknowledgement}

- Financial or Other Competing Interests: None

- Was Ethics Committee Approval obtained for this study? Yes

- Was informed consent obtained from the subjects involved in the study? Yes

- $\quad$ For any images presented appropriate consent has been obtained from the subjects. NA

\section{References}

[1] Shi Z, Hu Z. A review of studies on animal reservoirs of the SARS coronavirus. Virus Res 2008; 133: 74-87.

[2] Donnelly CA, Ghani AC, Leung GM, et al. Epidemiological determinants of spread of causal agent of severe acute respiratory syndrome in Hong Kong. Lancet 2003; 361: 1761-66.

[3] Cauchemez S, Fraser C, Van Kerkhove MD, et al. Middle East respiratory syndrome corona virus: quantification of the extent of the epidemic, surveillance biases, and transmissibility. Lancet Infect Dis 2014; 14: $50-56$.

[4] Wu P, Hao X, Lau EHY, et al. Real-time tentative assessment of the epidemiological characteristics of novel coronavirus infections in Wuhan, China, as at 22 January 2020. Euro Surveill2020; 25: 2000044.

[5] Hamming I, Timens W, Bulthuis ML, Lely AT, Navis G,van Goor H. Tissue distribution of ACE2 protein, the functional receptor for SARS coronavirus: a first step in understanding SARS pathogenesis. J Pathol 2004; 203: 631-37.

[6] Zhou F, Yu T, Du R, Fan G, Liu Y, Liu Z. Clinical course and risk factors for mortality of adult inpatients with COVID-19 in Wuhan, China: a retrospective cohort study. Lancet. 2020;395:1054-1062.

[7] Guan WJ, Liang WH, Zhao Y, et al. Comorbidity and its impact on 1590 patients with COVID-19 in China: a nationwide analysis. Eur Respir J. 2020;55(5):2000547.

[8] Templeton AJ, McNamara MG, Šeruga B, Vera-Badillo FE, Aneja P, Ocaña A. Prognostic role of neutrophil-tolymphocyte ratio in solid tumors: a systematic review and meta-analysis. J Natl Cancer Inst. 2014;106

[9] Mohitosh Biswas M, Shawonur Rahaman S, Biswas TK, Haque Z, Ibrahim B. Association of Sex, Age, and Comorbidities with Mortality in COVID-19 Patients: A Systematic Review and Meta-Analysis. Intervirology. 2021;64:36-47 
[10] Bonanad C, García-Blas S, Tarazona-Santabalbina F, Sanchis J, Bertomeu-González V, Fácila L, Ariza A, Núñez J, Cordero A. The Effect of Age on Mortality in Patients With COVID-19: A Meta-Analysis With 611,583 Subjects. J Am Med Dir Assoc. 2020 Jul;21(7):915-918.

[11] Osibogun A, Balogun M, Abayomi A, Idris J, Kuyinu Y, Odukoya O, et al.Outcomes of COVID-19 patients with comorbidities in southwest Nigeria. PLoS ONE 2021; 16(3): e0248281

[12] Gold MS, Sehayek D, Gabrielli S, Zhang X, McCusker C, Ben-Shoshan M. COVID-19 and comorbidities: a systematic review and meta-analysis. Postgrad Med. 2020 Nov;132(8):749-755.

[13] Hariyanto TI, Kurniawan A. Anemia is associated with severe coronavirus disease 2019 (COVID-19) infection. Transfus Apher Sci. 2020;59(6):102926.

[14] Galani I.E., Andreakos E. Neutrophils in viral infections: Current concepts and caveats. J. Leukoc. Biol. 2015;98:557-564.

[15] Naumenko V., Turk M., Jenne C.N., Kim S.J. Neutrophils in viral infection. Cell Tissue Res. 2018;371:505-516.

[16] Wang J., Jiang M., Chen X., Montaner L.J. Cytokine storm and leukocyte changes in mild versus severe SARS-CoV-2 infection: Review of 3939 COVID-19 patients in China and emerging pathogenesis and therapy concepts. J. Leukoc. Biol. 2020;108:17-41.

[17] Singh K., Mittal S., Gollapudi S., Butzmann A., Kumar J., Ohgami R.S. A meta-analysis of SARS-CoV-2 patients identifies the combinatorial significance of Ddimer, C-reactive protein, lymphocyte, and neutrophil values as a predictor of disease severity. Int. J. Lab. Hematol. 2020

[18] Guan J., Wei X., Qin S., Liu X., Jiang Y., Chen Y., Chen Y., Lu H., Qian J., Wang Z., Lin X. Continuous tracking of COVID-19 patients' immune status. Int. Immunopharmacol. 2020;89 doi: 10.1016/j.intimp.2020.107034.

[19] He Z, Zhao C, Dong Q, Zhuang H, Song S, Peng G, et al. Effects of severe acute respiratory syndrome (SARS) coronavirus infection on peripheral blood lymphocytes and their subsets. International journal of infectious diseases: IJID: 2005;9:323-30.

[20] Huang C, Wang Y, Li X, Ren L, Zhao J, Hu Y, et al. Clinical features of patients infected with 2019 novel coronavirus in Wuhan, China. The Lancet. 2020;395(10223):497-506.

[21] Sahu BR, Kampa RK, Padhi A, Panda AK. C-reactive protein: A promising biomarker for poor prognosis in COVID-19 infection. Clin Chim Acta. 2020;509:91-94. doi:10.1016/j.cca.2020.06.013

[22] Wang, L. C-reactive protein levels in the early stage of COVID-19. Medecine et Maladies Infectieuses, June 2020; Volume 50(4)

[23] Chaolin Chen, W., Zheng, K.I., Liu, S. et al. Plasma CRP level is positively associated with the severity of COVID-19. Ann Clin Microbiol Antimicrob.2020;19-18.

[24] Yao, Y., Cao, J., Wang, Q. et al. D-dimer as a biomarker for disease severity and mortality in COVID-19 patients: a case control study. j intensive care.2020; (8)49 .

[25] Yu HH, Qin C, Chen M, Wang W, Tian DS. D-dimer level is associated with the severity of COVID-19. Thromb Res. 2020;195:219-225. doi:10.1016/j.thromres.2020.07.047

[26] Yang AP, Liu JP, Tao WQ, Li HM. The diagnostic and predictive role of NLR, d-NLR and PLR in COVID-19 patients. Int Immunopharmacol. 2020;84:106504.

[27] Imran MM, Ahmad U, Usman U, Ali M, Shaukat A, Gul N. Neutrophil/lymphocyte ratio-A marker of COVID-19 pneumonia severity. Int J Clin Pract. 2021 Apr;75(4):e13698.

[28] Li, X., Liu, C., Mao, Z. et al. Predictive values of neutrophil-to-lymphocyte ratio on disease severity and mortality in COVID-19 patients: a systematic review and meta-analysis. Crit Care 2020; (24)647.

[29] Usul E, Şan İ, Bekgöz B, Şahin A: Role of hematological parameters in COVID-19 patients in the emergency room. Biomark Med. 2020, 14:1207-15

[30] Pimentel G.D., Dela Vega M.C.M., Laviano A. High neutrophil to lymphocyte ratio as a prognostic marker in COVID-19 patients. Clinical Nutrition ESPEN, 2020 ;40:101-102 